\title{
Practical management of agrichemical risk: bridging the gap between regulation expectations and industry practice
}

\author{
D.W.L. Manktelow ${ }^{1}$, N.M. Park², J.M. Maber ${ }^{3}$, J.T.S. Walker² and A.J. Hodson ${ }^{4}$ \\ ${ }^{1}$ Manktelow and Associates Ltd, PO Box 3415, Napier, New Zealand \\ ${ }^{2}$ Plant E Food Research, Private Bag 1401, Havelock North, New Zealand \\ ${ }^{3}$ John Maber and Associates Ltd, 2063 State Highway 23, Rd 12, Hamilton, New Zealand \\ ${ }^{4}$ HortPlus Ltd, 1091 Riverslea Rd S, Hastings, New Zealand \\ Corresponding author: david@freshlearn.co.nz
}

Agrichemical users face increasing pressures to adhere to, and document, safe and responsible use practices. Many requirements are set by the Resource Management (RMA) and Hazardous Substances and New Organisms (HSNO) legislation. Additional use and user requirements are dictated by market expectations for residues and adherence to different GAP programmes. Widespread adoption of industry relevant user training programmes is arguably the most effective way to achieve safe and effective agrichemical use in New Zealand. RMA requirements under all Regional Plans in the country require some level of agrichemical user training, with HSNO legislation requiring separate approved handler $(\mathrm{AH})$ certification for at least one person on most properties. With over 50,000 farms and horticultural properties in NZ, the estimated agrichemical user trainee population is well over 100,000 people. GROWSAFE and AH certificate numbers from 2004-09 after the 2004 enactment of the HSNO legislation for agrichemicals averaged 9,900 per annum. These certificates are required to be renewed every 5 years, but average trainee numbers from 2008-12 dropped to only 4,950 per annum. Training requirements and outcome expectations are reviewed in light of these declining trainee numbers and a new, industry-focussed, training initiative is described.

\section{Spray Plan Manager: a decision-support tool for regulatory compliance and improving agrichemical use practices}

\author{
A.J. Hodson ${ }^{1}$, M.J. Barley ${ }^{1}$, L.R. Hodson-Kersey ${ }^{1}$, J.T.S. Walker ${ }^{2}$, D.W.L. Manktelow ${ }^{3}$ and N.M. Park ${ }^{2}$ \\ ${ }^{1}$ HortPlus NZ Ltd, 1091 Riverslea Road South, Hastings 4271, New Zealand \\ ${ }^{2}$ Plant E Food Research, Private Bag 1401, Havelock North, New Zealand \\ ${ }^{3}$ Manktelow \& Associates, PO Box 3415, Napier Mail Centre, New Zealand \\ Corresponding author: hortplus@gmail.com
}

Spray Plan Manager (SPM) is a decision support tool that helps users manage and document agrichemical use plans for compliance and for environmental and user risk reduction. Refined and re-launched in 2013 at www.sprayplan.co.nz, SPM has a base user group of 1700 registered plans across 76 crop types. SPM takes agrichemical users through a step-wise property spray plan development. SPM uses online GIS mapping to assist in agrichemical risk management around identified sensitive areas. SPM uses agrichemical HSNO hazard classifications to describe personal protective equipment requirements for agrichemical mixing and application operations. For ongoing management of boundary and sensitive areas, spray drift risks can be estimated using forecast wind speed, wind direction, humidity and temperature. SPM ranks drift conditions on a scale from 1 (suitable) to 4 (unsuitable), and displays the user-supplied forecast directional risks on the property map. This has introduced a near real-time management component into annual spray plan operations. Annually produced property spray plans are an agrichemical use requirement under most regional plans. The new SPM was designed to assist users in this compliance task while also improving user education and outcomes around the safe, effective and responsible use of agrichemicals. 